\title{
Lobular Carcinoma Cell
}

National Cancer Institute

\section{Source}

National Cancer Institute. Lobular Carcinoma Cell. NCI Thesaurus. Code C36879.

A carcinoma cell that originates from the breast lobules. Lobular carcinoma cells are usually smaller than those of ductal breast carcinoma, are less pleomorphic, and have fewer mitotic figures. 